\title{
ASPECTOS SOCIOECONÔMICOS, PRODUTIVOS E SANITÁRIOS DA FABRICAÇÃO DE QUEIJO COALHO EM JAGUARIBE, CEARÁ
}

\author{
Francisca Klécia Bernardino da Silva ${ }^{1}$, Luana Maria de Lima Santos ${ }^{1}$, \\ VALDINEIA FREITAS SOARES ${ }^{1}$ \\ ${ }^{1}$ Instituto Federal de Educação, Ciência e Tecnologia do Ceará - IFCE \\ <kleciabernardina@hotmail.com><luanajbe@gmail.com><valdineiasoares@yahoo.com.br>
}

DOI: 10.21439/conexoes.v13i3.1132

\begin{abstract}
Resumo. A produção artesanal do queijo de coalho em Jaguaribe tem se constituído em uma importante estratégia para o desenvolvimento socioeconômico de muitas famílias, desde seu início quando se destinava ao aproveitamento do excedente de leite, até os dias atuais, como estratégia de agregação de valor ao leite in natura. Frente à importância desta atividade para o município, o presente estudo objetivou conhecer os aspectos socioeconômicos, produtivos e sanitários da fabricação do queijo de coalho em Jaguaribe, Ceará. Participaram desta pesquisa vinte e cinto produtores de queijo cujos estabelecimentos situam-se na sede do munícipio. Os aspectos socioeconômicos, produtivos e de infraestrutura foram avaliados por meio de questionários semiestruturados aplicados aos participantes. Diante disto se conclui que, embora a produção de queijo de coalho apresente caráter informal, ela contribui significativamente para a geração de renda local afirmando-se como atividade familiar. De acordo com os produtores, a adoção de políticas públicas, e a facilidade de acesso ao crédito podem contribuir para o aumento da competitividade e a sua consolidação no mercado.
\end{abstract}

Palavras-chaves: Atividade familiar. Queijo. Produção artesanal.

\begin{abstract}
Artesanal production of Coalho type cheese in Jaguaribe has been an important strategy for socio-economic development of many families, since its beginning when it was intended for profit of milk surplus, to the present day, as value-adding strategy to milk in natura. Considering the relevance of this activity for the city, this study aimed to identify the socioeconomic, sanitary and the productive aspects of rennet cheese manufacturing at Jaguaribe, Ceará. The research was done by interviewing twenty-five cheese producers whose establishments are located in the city. The given aspects and also infrastructure information were obtained from cheese producers by answering an semi-structured questionnaire. Therefore, it is concluded that although production of Coalho type cheese is informal, it contributes significantly to local income generation, asserting itself as a family activity. According to producers, the adoption of public policies and easier access to credit facility may contribute to increasing competition and consolidation in the market.
\end{abstract}

Keywords: Family activity. Cheese. Craft production.

\section{INTRODUÇÃO}

De acordo com Araújo (2011), o queijo de coalho é produzido em larga escala sendo muito apreciado em vários estados da região Nordeste, tais como Ceará, Rio Grande do Norte, Pernambuco e Paraíba. Grande parte dessa produção tem origem na fabricação artesanal, oriunda da produção caseira, em propriedades rurais de pequeno porte ou da Agricultura de Base Fami- liar (ARAÚJO, 2011). Segundo Machado et al. (2004), o queijo caracteriza-se como o derivado do leite mais aceito pela população, devido ao seu sabor e valor nutricional. Nesse contexto, Silva, Silva e Ferreira (2012) afirmam que o Ceará destaca-se como grande produtor e consumidor de queijos.

Conforme Decreto $\mathrm{n}^{0} 9.013 /$ março/2017 se entende por queijo de coalho, o produto obtido por meio de coagulação do leite induzida através da utilização do coa- 
lho animal ou outras enzimas coagulantes apropriadas, podendo ou não ser complementado pela ação de bactérias lácteas selecionadas, e comercializados normalmente, com até 10 dias a partir da fabricação. Segundo Cavalcante (2007), “o queijo coalho é fabricado com massa semicozida e tradicionalmente consumido fresco ou maturado", sendo fabricado a partir de leite bovino cru e/ou leite pasteurizado (BRASIL, 2017).

Em Jaguaribe, a produção de queijo de coalho está associada historicamente às instalações das fazendas para a criação de gado, passando pelo período das charqueadas no século XIX (era de ouro da região). Assim sendo, a produção a princípio estava relacionada à cultura de subsistência, em que quase todos tinham acesso ao queijo de coalho e à manteiga, para consumo de seus familiares e agregados (BASTOS; ULISSES; FONTENELE, 2013). Conforme relatos de Ulisses (2010), após o fim da 'era de ouro', os produtos associados à criação de gado, como o leite e o queijo de coalho, surgem como alternativas aos produtores do Vale, voltados para a pequena comercialização. Até o momento nos parece que a produção do queijo de coalho, a partir dos anos 70 do século XX, desponta como elemento essencial da economia do município.

Deste modo, a produção artesanal do queijo de coalho em Jaguaribe, tem se constituído em uma importante estratégia para o desenvolvimento socioeconômico de muitas famílias. Segundo Menezes (2011), esse meio de subsistência tem funcionado como estratégia de afirmação socioeconômica dos pequenos agricultores, principalmente no sertão nordestino, como é o caso dos muitos produtores de queijos de coalho da cidade de Jaguaribe, Ceará.

A importância do queijo de coalho para o Nordeste é tão grande, que passou a ser considerado patrimônio da população nordestina (MENEZES, 2011). Segundo Ulisses (2010), a iguaria tem sua inserção na tradição e na economia local. Em Jaguaribe, o queijo de coalho tem se constituído em um meio de sustento para muitas famílias e aquecido o comércio local constituindo-se uma das principais fontes de renda na microrregião do vale jaguaribano.

Diante do exposto, o presente estudo objetivou conhecer os aspectos socioeconômicos, produtivos e sanitários da fabricação do queijo coalho de Jaguaribe.

\section{METODOLOGIA}

Com base no tipo de abordagem realizada, esta pesquisa se caracteriza como um estudo de caso de abordagem quali-quantitativa. Esse tipo de abordagem foi escolhido, por possibilitar uma melhor compreensão do universo amostral.

Os levantamentos foram realizados nos estabelecimentos queijeiros localizados na sede do munícipio de Jaguaribe. Foram visitadas 25 queijeiras, o que corresponde a $37,8 \%$ do número de estabelecimentos do município (QUEIJARIBE, 2013). Para realização das visitas foi solicitada a colaboração dos proprietários para participarem do estudo. Foi firmada parceria com os produtores através do termo de livre esclarecimento e através desta foram realizadas visitas aos estabelecimentos e aplicação de questionários, com o fim de se obter os dados necessários à realização do estudo. A coleta dos dados ocorreu no período de 01 de julho a 30 de setembro do ano de 2015.

Um questionário semiestruturado com 15 questões foi elaborado para que se obtivesse o maior número de informações acerca dos aspectos socioeconômicos, produtivos e sanitários relacionados à produção do queijo coalho, praticada pelos pequenos produtores no município de Jaguaribe.

No que se refere aos aspectos socioeconômicos, se buscou identificar a localização do estabelecimento, o nível de escolaridade do seu proprietário, sua participação ou não na associação local, se possui funcionários, onde aprendeu a técnica, há quanto tempo desenvolve a atividade, dentre outros.

Entre os aspectos produtivos foram considerados à quantidade de leite empregada na produção de queijo de coalho, a origem do leite utilizado na produção, o preço pago pela matéria-prima, a quantidade produzida, o preço de comercialização do produto e o mercado de vendas.

No tocante aos aspectos sanitários relacionados à infraestrutura da queijeira buscou-se verificar se o estabelecimento possui equipamento para refrigeração do leite, qual a natureza dos utensílios utilizados na fabricação do queijo, se utilizam vestimentas adequadas à atividade, qual a rotina de trabalho praticada nos estabelecimentos, sobre a natureza dos materiais utilizados no interior das instalações (paredes e pisos) e como é realizado o processo de higienização do estabelecimento.

Buscou-se ainda conhecer a opinião dos produtores de queijo de coalho acerca da necessidade dos cursos de qualificação, da adequação das instalações à utilização das Boas Práticas de Fabricação, e de políticas públicas, que possam garantir a consolidação da tradição e a competitividade no mercado. 


\section{RESULTADOS E DISCUSSÃO}

\subsection{Aspectos Socioeconômicos}

O município de Jaguaribe está situado na microrregião do Médio Jaguaribe no estado do Ceará, tendo como principal atividade socioeconômica a produção leiteira e de laticínios, reconhecida nacionalmente pela qualidade de seus queijos. A população total estimada em 2015, segundo o IBGE foi de 34.561 habitantes (IBGE, 2015), o Índice de Desenvolvimento Humano do município em 2010 foi 0,62 , ocupando o $70^{\circ}$ lugar no estado (IBGE, 2015). A economia do município está baseada em atividades nos setores primário, secundário e terciário. A agropecuária, o beneficiamento dos produtos primários e o comércio/serviço representam respectivamente, $11,4 \%, 17,9 \%$ e 70,7\% do Produto Interno Bruto (PIB) (IBGE, 2015).

Conforme dados fornecidos pela Associação dos Produtores de Leite e Derivados de Jaguaribe - Queijaribe, no ano de 2013 havia 66 produtores de queijo coalho no município de Jaguaribe, sendo 31 estabelecimentos localizados na sede, e 35 na zona rural. Das 31 queijeiras localizadas na zona urbana de Jaguaribe, foram entrevistados 25 proprietários, dos quais 32\% destes são associados à cooperativa (QUEIJARIBE, 2013).

Atualmente, a grande maioria dos produtores de queijo de coalho de Jaguaribe é composta pelo sexo masculino $(92 \%)$, porém, algumas poucas mulheres, ainda exercem esta atividade (8\%). Outrora, quando a produção de leite se destinava ao autoconsumo, sob a forma in natura ou à produção de derivados, a exemplo do queijo de coalho e manteiga caseira, essa era uma tarefa de responsabilidade das mulheres. Com as alterações do sistema produtivo, esta atividade passou a ser de responsabilidade do homem. Hoje são articulados espaços exclusivos para a produção deste alimento, surgiram novos tipos de queijos e foram construídas redes de comercialização (MENEZES; ALMEIDA, 2008).

Atualmente, a produção do queijo de coalho na cidade de Jaguaribe é tão expressiva, que se constatou neste estudo a existência de produtores de variadas faixas de idade (Tabela01). A idade média obtida entre os entrevistados foi de 48,6 anos, e a idade mínima foi de 21 anos, sendo a idade máxima de 73 anos. Esses dados estão de acordo com os registrados no estudo de Rosanova e Ribeiro (2015) realizado em Palmas-TO, cuja média de idade dos produtores de queijo foi de 48 anos, sendo a mínima de 21 anos e a idade máxima de 76 anos. Ainda conforme os referidos autores, a idade do produtor reflete sua experiência na atividade e sua capacidade de lidar com novas tecnologias e compreender novas exigências de mercado, entre outras coisas.

Tabela 1: Faixa etária dos produtores de queijo de coalho do município de Jaguaribe, Ceará.

\begin{tabular}{cc}
\hline Faixa de Idade & Número de Registros \\
\hline 20 a 30 & 2 \\
30 a 40 & 3 \\
40 a 50 & 4 \\
50 a 60 & 12 \\
60 a 70 & 3 \\
70 a 80 & 1 \\
\hline TOTAL & $\mathbf{2 5}$ \\
\hline \multicolumn{2}{r}{ Fonte: Próprios autores. }
\end{tabular}

No que se refere ao nível de instrução dos entrevistados, $16 \%$ (4) dos produtores afirmaram possuir o ensino fundamental completo, $28 \%$ (7) não concluíram este nível de estudo, 36\% (9) dos entrevistados possuem o ensino médio completo e $16 \%$ (4) não chegaram a concluí-lo. Apenas 4\% (1) da amostra cursa atualmente o ensino superior. Assim como a idade, a escolaridade está relacionada ao acesso ao conhecimento e à possibilidade de adequação às mudanças tecnológicas (ROSANOVA; RIBEIRO, 2015).

Todavia, o nível de escolaridade dos produtores certamente não pode ser considerado um requisito indispensável, para o estabelecimento do produtor, mas agricultores com baixa escolaridade, porém com muita vivência prática, também conseguem se estabelecer no mercado. Ressalta-se, contudo, que os produtores com maior nível de conhecimento conseguem quebrar antigos paradigmas e serem mais competitivos (MAZZOLENI; NOGUEIRA, 2006).

Tradicionalmente, os agricultores familiares de Jaguaribe utilizam a terra para a produção de alimentos e a criação de gado leiteiro (GUERRA; SOUZA; LUSTOSA, 2012). Em muitas comunidades, ao longo dos anos, a fabricação e comercialização de queijos tem representado uma atividade de grande relevância econômica local e regional, sendo praticada por um considerável número de famílias de pequenos produtores, estabelecidos principalmente na zona rural constituindo-se esta atividade em sua principal fonte de renda (Freitas Filho et al., 2012).

Entretanto, a produção do queijo coalho em Jaguaribe, não se constitui a única alternativa para a maioria dos entrevistados, outras atividades também são desenvolvidas para complementar a renda familiar e frequentemente, estas outras atividades estão de algum modo relacionadas à produção de queijo de coalho. Muitos produtores utilizam o soro proveniente da fabricação do 
queijo para alimentar criações de suínos, ovinos e até bovinos, outros comercializam seus queijos na capital e cidades vizinhas (Tabela 02 ).

Tabela 2: Atividades complementares à renda desenvolvidas pelos produtores de queijo de coalho de Jaguaribe, Ceará.

\begin{tabular}{cc}
\hline $\begin{array}{c}\text { Atividades } \\
\text { Completares }\end{array}$ & $\begin{array}{c}\text { Número de } \\
\text { Registros }\end{array}$ \\
\hline Criação de bovinos & 4 \\
Criação de bovinos e ovinos & 2 \\
Criação de bovinos, ovinos e suínos & 4 \\
Criação de suínos & 1 \\
Criação de bovinos e suínos & 2 \\
Criações diversas & 5 \\
Criação de camarões & 1 \\
Comércio varejista & 3 \\
Locação de imóveis & 1 \\
Fretes & 1 \\
Produção de leite & 14 \\
Fonte: Próprios autores.
\end{tabular}

Neste sentido, Seixas et al. (2014) constataram que em $80 \%$ dos produtores de queijo entrevistados na ilha de Marajó, no Pará, não fabricavam somente o queijo, incluindo outras atividades agropecuárias e o comércio. Ainda conforme os referidos autores, essa realidade se configura como uma estratégia de sobrevivência para permanência desses produtores no campo, uma vez que, a diversificação de atividades (SOARES; MELO; CHAVES, 2009) propicia o incremento da renda familiar (SEIXAS et al., 2014). De acordo com Menezes (2011), a manutenção de tais produtos nos mercados tradicionais e sua inserção em novos nichos, impulsiona a produção e a comercialização do queijo e fortalece essa estratégia de reprodução no meio rural, ao gerar renda e postos de trabalho.

A maioria dos produtores de queijo de coalho entrevistada em Jaguaribe afirmou exercer a atividade há mais de 20 anos (Tabela 03). Outro fato que merece destaque é que essa atividade tem sido passada de pai para filho, e essa tradição já vem de seus antepassados há pelo menos 200 anos (BASTOS; ULISSES; FONTENELE, 2013). A tradição de fabricar queijos de coalho em Jaguaribe é histórica, os relatos datam do século XIX, quando a fabricação do queijo era realizada apenas no período das chuvas, para o aproveitamento do excedente da produção de leite, para autoconsumo (BASTOS; ULISSES; FONTENELE, 2013).

Neste sentido, muitos produtores afirmaram ter adquirido a técnica de produção do queijo de coalho com seus familiares, avós, pais e outros parentes, ou em lo-
Tabela 3: Tempo de permanência dos produtores na produção de queijo de coalho em Jaguaribe, Ceará.

\begin{tabular}{cc}
\hline $\begin{array}{c}\text { Tempo de Permanência } \\
\text { na Produção }\end{array}$ & Número de Registros \\
\hline $0-10$ & 6 \\
$10-20$ & 5 \\
$20-30$ & 6 \\
$30-40$ & 7 \\
A mais de 40 anos & 1 \\
\hline TOTAL & $\mathbf{2 5}$ \\
\hline
\end{tabular}

Fonte: Próprios autores.

cais onde havia trabalhado, outros aprenderam por si só, através de tentativas e erros, e aqueles que não sabem fazer contratam a mão de obra necessária (Tabela 04). No estudo de Seixas et al. (2014), a grande maioria dos entrevistados possuíam mais de dez anos de experiência na fabricação de queijos, sendo a arte de produzir esses queijos aprendida com algum membro da família (SEIXAS et al., 2014).

Tabela 4: Origem da técnica de fabricação do queijo de coalho produzido em Jaguaribe, Ceará.

\begin{tabular}{cc}
\hline Origem da Técnica & Número de Registros \\
\hline Com os familiares & 13 \\
Laticínios Jaguaribe & 3 \\
Expatrão & 3 \\
Aprendeu só & 3 \\
Não sabe fazer & 1 \\
Com outros & 2 \\
\hline TOTAL & $\mathbf{2 5}$ \\
\hline
\end{tabular}

Fonte: Próprios autores.

Contudo, no presente estudo $60 \%$ dos produtores entrevistados afirmaram já haver participado de oficinas, treinamentos e workshoppings promovidos pela associação local, em parceria com instituições como o SEBRAE, a Embrapa, a Ematerce e a Secretária de Agricultura do município, o que contribuiu de modo significativo para o aperfeiçoamento das técnicas de produção do queijo de Jaguaribe foram citadas melhorias como, a correta higienização do estabelecimento e dos utensílios utilizados para a produção do queijo de coalho, emprego das técnicas de padronização da produção, além de técnicas para a comercialização do produto.

Alguns estabelecimentos queijeiros em Jaguaribe, além da partição do proprietário e seus familiares, absorvem mão de obra extra, empregando até no máximo sete funcionários (Tabela 05). Entretanto, a produ- 
ção artesanal de queijo coalho no município pode ser caracterizada como empreendimento familiar, pois de acordo com Soares, Melo e Chaves (2009), um estabelecimento familiar corresponde a uma unidade de produção agrícola, onde propriedade e trabalho estão intimamente ligados à família, podendo absorver mão de obra externa. Conforme se constatou-se no estudo atual, alguns produtores, em função do volume de produção, contratam mão-de-obra extra.

Tabela 5: Número de funcionários empregados na produção de queijo de coalho em Jaguaribe, Ceará.

\begin{tabular}{cc}
\hline Número de Funcionários & Número de Registros \\
\hline 0 & 5 \\
1 a 2 & 14 \\
2 a 4 & 3 \\
>5 & 3 \\
\hline TOTAL & $\mathbf{2 5}$
\end{tabular}

Fonte: Próprios autores.

Estratégias como estas são importantes no meio rural do Agreste e do Sertão nordestino, por dinamizar a economia em municípios de pequeno porte constituindo a renda principal ou complementar das famílias, contribuindo para a circulação de bens no próprio município e desacelerando o êxodo rural (MENEZES, 2011).

\subsection{Aspectos Produtivos}

De acordo com o censo agropecuário realizado em 2006, o Brasil produziu naquele ano 111.463 toneladas (t) de queijo, oriundos da agricultura familiar entre matéria-prima própria e adquirida, desse total, $35.800(\mathrm{t})(32,12 \%)$ foram produzidas no Nordeste, sendo 5.245 (t) produzidas no estado do Ceará. Levando em consideração a produção de queijo oriundo da agricultura familiar no Brasil, com matéria-prima própria 97.058 (t) e com matéria-prima adquirida 14.405 (t), ficando evidente que o a produção de queijo é um negócio rentável para o agricultor familiar, representado uma atividade de importância social, econômica e cultural (CENSO AGROPECUÁRIO, 2006).

Em Jaguaribe, assim como em outros lugares de pastoreio/pecuária, o queijo de coalho foi uma das escolhas encontradas entre os produtores, para evitar que o excedente do leite estragasse (BASTOS; ULISSES; FONTENELE, 2013). Além disso, a fabricação de queijos de coalho constitui-se em uma alternativa de agregação de valor ao leite, pois, o valor pago pelo quilo de queijo coalho é bem mais significativo economicamente, em relação ao preço pago pela comercialização do leite in natura.
A produção de queijo artesanal tem sido reconhecida atualmente, como uma ferramenta socioeconômica da agricultura familiar inserida no mercado informal, por não atender à legislação vigente (MENEZES, 2011).

O leite utilizado para a fabricação do queijo coalho em Jaguaribe é oriundo dos rebanhos locais, alguns produtores de queijo também produzem o leite necessário à fabricação de queijo, além de adquirem matériaprima de outras propriedades vizinhas, para atender as suas demandas de produção. De acordo com Menezes (2011), nos territórios onde a produção de queijo é expressiva, além dos outros derivados do leite, como o creme de nata, a manteiga, o doce de leite, entre outras formas, estas constituem-se atividades complementares, porém interligadas, que colaboram para geração de renda.

Atualmente, em relação aos aspectos produtivos, no que se refere ao leite utilizado para a fabricação de queijo de coalho, a maior parte $(56 \%)$ da matéria-prima utilizada na fabricação do queijo é produzida pelos rebanhos locais, o outro montante (44\%) é adquirido em sítios, fazendas e localidades vizinhas (Tabela 06). Seixas et al. (2014) também constataram um quadro semelhante na ilha de Marajó, Pará.

Alguns dos estabelecimentos visitados no presente estudo apresentam uma melhor infraestrutura, o que lhes permite maior capacidade de processamento diário, assumindo estes estabelecimentos, características de agroindústria familiar. Alguns produtores processam cerca de 100 1/dia, enquanto outros chegam a utilizar mais de 5.000 1/dia. No presente estudo foram considerados estabelecimentos de pequeno porte, os que processam até $500 \mathrm{1} / \mathrm{dia}$. Aqueles que processam até 7.200 litros de leite/dia podem ser considerados estabelecimentos de médio e grande portes.

De acordo com relatos de Bastos, Ulisses e Fontenele (2013), as adequações na estrutura física dos espaços de fabricação do queijo de coalho ocorreram de forma lenta, a princípio a produção de queijo se dava na cozinha da casa, evoluindo posteriormente para os anexos, que se assemelham aos "puxados". As referidas autoras relatam ainda que, afora isso, ao mudar a condição de consumo doméstico do queijo para produção comercial, não houve a princípio mudanças nos costumes e hábitos de preparo do queijo de coalho, como também na configuração do espaço destinado à fabricação e nos equipamentos utilizados.

Conforme Perry (2004), no nordeste brasileiro, a maior parte da produção de queijos artesanais é obtida em queijarias de pequeno e médio porte, o que sinaliza 

CEARÁ

Tabela 6: Origem do leite destinado à fabricação do queijo de coalho em Jaguaribe, Ceará.

\begin{tabular}{cc}
\hline Origem do Leite & Número de Registros \\
\hline Produção própria & 4 \\
Própria, e aquisição em fazendas e sítios & 9 \\
Aquisição em fazendas e sítios & 9 \\
Aquisição em Jaguaribe e outras localidades & 2 \\
Própria, de Jaguaribe e outras localidades & 1 \\
\hline TOTAL & $\mathbf{2 5}$ \\
\hline Fonte: Próprios autores.
\end{tabular}

Fonte: Próprios autores.

ser essa atividade importante em termos socioeconômicos (ARAÚJO, 2011).

Com base nos dados obtidos em vinte e cinco estabelecimentos situados na sede do município de Jaguaribe estima-se que sejam processados diariamente cerca de 39.770 1/leite/dia, a partir dos quais são produzidos $3.977 \mathrm{~kg} / q u e i j o /$ dia considerando-se que são utilizados na produção de queijo coalho, 10 1/kg de leite para cada $1 / \mathrm{kg}$ de queijo produzido (Tabela 07). O que corresponde mensalmente a um volume de $1.193 .1001 \mathrm{de}$ leite, resultando na produção de $119.310 \mathrm{~kg} /$ queijo em um período de 30 dias, o que gera uma renda mensal em torno de $\mathrm{R} \$ 16.106,85$ considerando-se para o cálculo, o valor médio praticado no mercado atual de $\mathrm{R} \$$ $13,50 / \mathrm{kg}$. Porém o preço informado no presente estudo variou localmente de $\mathrm{R} \$ 10,00$ a $\mathrm{R} \$ 17,00 / \mathrm{kg}$.

Tabela 7: Capacidade diária de processamento de leite destinado à produção de queijo de coalho nos estabelecimentos situados em Jaguaribe, Ceará.

\begin{tabular}{cc}
\hline $\begin{array}{c}\text { Capacidade Diária de } \\
\text { Processamento de Leite para a } \\
\text { Produção de Queijo Coalho }(\mathbf{L})\end{array}$ & $\begin{array}{c}\text { Número } \\
\text { de } \\
\text { Registros }\end{array}$ \\
\hline 100 a 500 & 7 \\
500 a 1.000 & 9 \\
1.000 a 1.500 & 2 \\
1.500 a 2.000 & 1 \\
>2.000 & 6 \\
\hline TOTAL & $\mathbf{2 5}$ \\
\hline Fonte: Próprios autores. &
\end{tabular}

Entretanto, essa é apenas uma pequena estimativa do real potencial de geração de renda desta atividade para o município, pois os valores aqui apresentados correspondem apenas a $37,8 \%$ das queijeiras situadas em Jaguaribe, considerando-se o total de estabelecimentos que produzem queijo essa receita pode ser maior. De acordo com Menezes (2011), outro fator que dificulta esta estimativa é a informalidade, uma vez que a grande maioria desses produtos são comercializados de modo informal, pois a produção na maioria das vezes, não atende às normas sanitárias vigentes. Segundo Araújo (2011), a produção deste tipo de queijo por pequenos agricultores tem sua principal base de comercialização o mercado informal, pois $90 \%$ dessa produção é comercializada informalmente. Porém ressalta-se que, para a população de Jaguaribe essa produção traz consigo valores históricos.

A frequência de comercialização dos queijos de coalho varia em função da capacidade de processamento da queijeira. A grande maioria dos produtores de queijo realiza suas vendas semanalmente, principalmente na capital do estado. Enquanto outros comercializam seus produtos diariamente no comércio local ou para atravessadores, e em municípios circunvizinhos (Tabela 08). Esses dados corroboram com os constatados por Menezes (2011).

Tabela 8: Local de comercialização do queijo de coalho produzido em Jaguaribe, Ceará.

\begin{tabular}{cc}
\hline Comercialização & $\begin{array}{c}\text { Número } \\
\text { de } \\
\text { Registros }\end{array}$ \\
\hline Local & 2 \\
Local e municípios vizinho & 1 \\
Local e estadual & 1 \\
Local e capital & 4 \\
Local, municípios vizinho e capital & 1 \\
Municípios vizinhos & 1 \\
Capital & 14 \\
Capital e estadual & 1 \\
\hline TOTAL & $\mathbf{2 5}$
\end{tabular}

Fonte: Próprios autores.

\subsection{Aspectos Sanitários (infraestrutura)}

Conforme estudo conduzidos por Araújo (2011), as agroindústrias familiares e os pequenos produtores dos estados nordestinos convivem ao longo dos anos, com 
três problemas que comprometem diretamente a produção do queijo: primeiro, visto ao não atendimento às práticas higiênico-sanitária na fabricação do queijo; segundo, pelas deficiências ocorridas na produção e que compromete a qualidade e a segurança alimentar, reduzindo a potencialidade mercadológica do produto; e em terceiro, pela falta de padronização dos queijos produzidos e comercializados.

Para Nasciemento Neto (2006), as Boas Práticas de Fabricação (BPF) constituem-se requisitos essenciais necessários para garantir a qualidade da matéria-prima e do produto final, devendo ser aplicadas em todas as etapas do processo produtivo, pois elas asseguram a qualidade almejada na produção de alimentos. Ainda conforme os referidos autores, o leite é um alimento considerado perfeito, do ponto de vista nutricional, por fornecer nutriente à alimentação humana, entretanto, quando produzido sem os devidos cuidados, o leite é capaz de permitir o desenvolvimento de bactérias indesejáveis podendo causar doenças e outros problemas, como o aumento da acidez, que pode comprometer a qualidade de seus derivados (queijo, manteiga, iogurte, etc.). Esses problemas podem causar grandes prejuízos para a indústria e para a saúde dos consumidores finais.

As instalações utilizadas para fabricação de queijos de coalho em Jaguaribe são em sua totalidade de alvenaria, com paredes e pisos revestidos de cerâmicas, apenas alguns poucos estabelecimentos não possuem revestimento sendo o piso de cimento e as paredes caiadas.

No que se refere à natureza do material utilizado para fabricação do queijo de coalho foram citados utensílios de plástico e de aço inoxidável $52 \%$, somente de aço inoxidável $40 \%$, plástico, alumínio e aço inoxidável, plástico e madeira, ambos, em um percentual de $4 \%$.

Também se investigou as vestimentas utilizadas para a fabricação do queijo de coalho, 32

A grande maioria dos estabelecimentos visitados, $72 \%$ não possui nenhum tipo de equipamento para o resfriamento do leite que será destinado à fabricação do queijo. Todo o leite que se destina à produção do queijo, ao chegar a queijeira é coado e submetido ao processo de coagulação. Os outros $28 \%$ dos entrevistados relataram se utilizar de freezers e câmeras frias, para preservar o leite até sua utilização.

No estudo atual verificou-se que em $72 \%$ dos estabelecimentos, todo o processo de recebimento do leite, fabricação do queijo de coalho, higienização das instalações e utensílios é realizado no período compreendido entre 07:00 horas às 22:00 horas. No período da manhã é processado o leite captado até às 09:00 horas, antes do intervalo para o almoço, todo esse leite já deve ter sido coagulado, dessorado, salgado e prensado. No período da tarde, uma nova coleta de leite é realizada, e reiniciase o processo, para a fabricação de outra remessa de queijos.

Entretanto, neste estudo foram constatados diferentes horários de funcionamento dos estabelecimentos ao longo do dia, sendo que algumas queijeiras funcionam exclusivamente no período da manhã, ou somente à tarde, os $28 \%$ restantes funcionam nos turnos manhã e atarde. $\mathrm{O}$ último procedimento diário realizado nas queijeiras é a higienização das instalações e utensílios. A higienização é realizada utilizando-se na maioria das unidades, água sanitária, sabão em pó e em barra, água quente, detergentes alcalinos, neutros ou sulfurados e a associação de alguns desses produtos.

Ao final das entrevistas perguntou-se aos produtores de queijo coalho de Jaguaribe, quais melhorias são necessárias para potencializar a produção e a comercialização do queijo por eles produzidos. Os entrevistados relataram a necessidade da adoção de políticas públicas de convivência com a seca; fomento à infraestrutura dos estabelecimentos; linhas de crédito destinadas aos produtores de queijo e criadores; redução dos custos de produção, como luz e combustíveis; e orientação técnica para produção do leite destinado a fabricação do queijo de coalho da porteira para dentro, entre outros.

Os produtores locais aguardam com grande expectativa pelo selo de certificação geográfica do queijo coalho de Jaguaribe, ação está que já foi iniciada pela Embrapa, e encontra-se em processo de finalização. Segundo relatos dos próprios produtores, o sabor característico do queijo coalho jaguaribano é conferido por componentes do pasto que ocorre na região, o que confere ao leite, e consequentemente ao queijo, o sabor característico do queijo de Jaguaribe. Tal fato está relacionado à necessidade de revalorizar a cultura queijeira, agregar valor à produção e oferecer alimentos "seguros".

Pois conforme Menezes (2011), o queijo de coalho é considerado como um patrimônio da população nordestina. Em face de sua importância socioeconômica e capacidade de aglutinar os atores sociais na elaboração e na comercialização, e como um alimento enraizado na alimentação nordestina, a produção de queijo requer movimentos em defesa da qualidade desse produto e, na elaboração de normativas condizentes a com essa realidade. 
ASPECTOS SOCIOECONÔMICOS, PRODUTIVOS E SANITÁRIOS DA FABRICAÇÃO DE QUEIJO COALHO EM JAGUARIBE, CEARÁ

\section{CONSIDERAÇÕES FINAIS}

A produção de queijo coalho no município de Jaguaribe possui relevância social, econômica e cultural para população jaguaribana, desde seu início, até os dias atuais. Esta atividade, considerada artesanal vem sendo desenvolvida por pequenos e médios agricultores e seus familiares. Portanto, representa uma forte estratégia de reprodução familiar. Apesar da informalidade, essa atividade incrementa a economia local e apresenta potencial para se consolidar no mercado nordestino.

Contudo, os produtores reconhecem que, a melhorias na infraestrutura das queijeiras e a implantação das boas práticas higiênico-sanitárias são necessárias para a obtenção de queijos de qualidade. Além da adoção de políticas públicas, tais como a certificação geográfica do queijo de Jaguaribe, e a abertura de acesso ao crédito, que podem assegurar sua permanência na atividade e melhorar a competitividade de seus produtos no mercado.

\section{REFERÊNCIAS}

ARAÚJO, J. B. C. Adoção de tecnologia para melhoria do processo de produção de queijo de coalho artesanal de agricultores familiares dos estados do ceará, piauí e rio grande do norte. In: 31 (Ed.). ENCONTRO NACIONAL DE ENGENHARIA DE PRODUCAO. Belo Horizonte: Anais eletrônicos, 2011. Disponível em: <www.abepro.org.br/biblioteca/enegep2011_tn_ stp_136_866_18841.pdf>. Acesso em: 20 jul. 2015.

BASTOS, M.; ULISSES, I. B.; FONTENELE, M. A. Queijo de coalho do jaguaribe: sabor perpetuado de uma tradição secular. Embrapa Agroindústria Tropical-Documentos (INFOTECA-E), Fortaleza: Embrapa Agroindústria Tropical, 2013., v. 1, p. 47, 2013.

BRASIL. Instrução Normativa n 30 de 26 de junho de 2001 do Departamento de Inspeção de produtos de origem animal do Aprova os Regulamentos Técnicos de Identidade e Qualidade de Manteiga da Terra ou Manteiga de Garrafa; Queijo de Coalho e Queijo de Manteiga. Diário Oficial [da] Republica Federativa do Brasil. Brasília, DF, 2001.

. Regulamento da Inspeção Industrial e Sanitária de Produtos de Origem Animal (RIISPOA). Decreto No 9.013/29 de Março/2017. Brasília, 2017.
CENSO AGROPECUÁRIO. Instituto Brasileiro de Geografia e Estatística - IBGE. Rio de Janeiro, 2006. P. 267.

Freitas Filho, J. R.; FILHO, J. S. de S.; ARCANJO, H. G. S. de; OLIVEIRA, H. B. de; LINO, F. R. L.; BEZERRA, J. I. L.; SILVA, J. J. P. da. Avaliação dos parâmetros físico químicos do queijo coalho artesanal produzido em calçado-pe. Revista Brasileira de Tecnologia Agroindustrial, v. 6, n. 1, p. 722-729, 2012.

GUERRA, M. D. F.; SOUZA, M. J. N. de; LUSTOSA, J. P. G. A pecuária, o algodão e a desertificação nos sertões do médio jaguaribe-ceará/brasil. Mercator, v. 11, n. 25, p. 103-112, 2012.

IBGE. Censo demográfico. 2015. Disponível em: <www.ibge.gov.br/home/estatística/pesquisas/ indicadores.php>. Acesso em: 20 out. 2013.

MACHADO, E. C.; FERREIRA, C.; FONSECA, L. M.; SOARES, F. M.; JÚNIOR, F. P. Características físico-químicas e sensoriais do queijo minas artesanal produzido na região do serro, minas gerais. Ciência e Tecnologia de Alimentos, SciELO Brasil, v. 24, n. 4, p. 516-521, 2004.

MAPA. Regulamento da Inspeção Industrial e Sanitária de Produtos de Origem Animal (RIISPOA). Aprovado pelo Decreto n. ${ }^{\circ} 30.691$ de 29 de março de 1952 e alterado pelos Decretos n.s 1.255 de 25.06.1962; 236 de 02.09.1994; 1812 de 08.02.1996; 2.244 de 04.06.1997. [S.1.], 2015. Disponível em: <http://www.agricultura.gov.br/ arq_editor/file/Aniamal/MercadoInterno/Requisitos/ RegulamentoInspecaoIndustrial.pdf>. Acesso em: 21 jul. 2015.

MAZZOLENI, E. M.; NOGUEIRA, J. M. Agricultura orgânica: características básicas do seu produtor. Revista de Economia e Sociologia Rural, SciELO Brasil, v. 44, n. 2, p. 263-293, 2006.

MENEZES, S. d. S. M.; ALMEIDA, M. G. A produção de queijos no sertão sergipano troca de mãos: Uma questão de gênero. Raega-O Espaço Geográfico em Análise, v. 16, n. 16, p. 47-54, 2008.

MENEZES, S. M. Queijo de coalho: tradição cultural e estratégia de reprodução social na região nordeste.

Revista de Geografia (Recife)-ISSN: 0104-5490, v. 28, n. 1, p. 40-56, 2011. 
Nasciemento Neto, F. d. Recomendações básicas para a aplicação das boas práticas agropecuárias e de fabricação na agricultura familiar. Embrapa informação tecnológica. Brasília, DF, 2006.

PERRY, K. S. P. Queijos: aspectos químicos, bioquímicos e microbiológicos. Química Nova, SciELO Brasil, v. 27, n. 2, p. 293-300, 2004.

QUEIJARIBE. Associação dos Produtores de Leite e Derivados de Jaguaribe. Levantamento da produção de leite e laticínios de Jaguaribe. Jaguaribe, 2013.

ROSANOVA, C.; RIBEIRO, D. C. Caracterização socioeconômica dos produtores de leite da agricultura familiar e análise da informalidade no município de palmas/to. In: 1 (Ed.). 1a JORNADA DE INICIAÇÃO CIENTÍFICA E EXTENSÃO DO IFTO. Palmas, TO: Anais eletrônicos..., 2015. v. 1. Disponível em: <www.ifto.edu.br/jornadacientifica/ wp.../JICE-2011-anais-eletrônicos.pdf >. Acesso em: 21 out. 2015.

SEIXAS, V. N. C.; CORREIA, L. F. M.; PERRONE, Í. T.; COUTINHO, R. M. P.; COSTA, R. G. B.; CARVALHO, A. F. de. Diagnóstico socioeconômico dos produtores de queijos do marajó. Revista do Instituto de Laticínios Cândido Tostes, v. 69, n. 5, p. 309-321, 2014.

SILVA, G.; SILVA, A. M. A.; FERREIRA, M. P. B. Processamento de Leite. Curitiba, 2012.

SOARES, I. F.; MELO, A. C. de; CHAVES, A. D. C. G. A agricultura familiar: Uma alternativa para o desenvolvimento sustentável no município de condado-pb. Informativo Técnico do Semiárido, v. 3, n. 1, p. 56-63, 2009.

ULISSES, I. B. Fonte oral, memória e trabalho: possibilidade de uma história do queijo em jaguaribe - ceará. In: 1 (Ed.). ENCONTRO NACIONAL

DE HISTORIA ORAL. TESTEMUNHOS: HISTÓRIA E POLITICA. Recife: UFPE: Anais eletrônicos..., 2010. v. 1. Disponível em: <http://www.encontro2010.historiaoral.org. br/resources/anais/2/1270419765_ARQUIVO_ textocompletoIVANEIDEBULISSES.pdf $>$. Acesso em: 22 jul. 2015. 